\title{
TGF- $\beta$ antibodies: a novel treatment for pulmonary fibrosis?
}

The lungs consist mainly of blood vessels and connective tissue. It is therefore not surprising that pulmonary fibrosis, either localised or diffuse, is a potential complication of a wide range of conditions. In some cases the cause of injury to the lung is known-for example, exposure to asbestos, coal dust, beryllium, cobalt, silica, paraquat, and mineral oils. Fibrosis may also complicate many respiratory diseases including extrinsic allergic alveolitis, sarcoidosis, the adult respiratory distress syndrome, allergic bronchopulmonary aspergillosis, and chronic fungal infections such as histoplasmosis and coccidioidomycosis. It may be seen after radiation pneumonitis or interstitial pneumonitis in patients with HIV infection, ${ }^{1}$ and can result from the use of drugs-for example, amiodarone used in the treatment of cardiac dysrrhythmias or chemotherapeutic agents including bleomycin. Diffuse pulmonary fibrosis may also be associated with any of the connective tissue disorders. It is most commonly seen in rheumatoid arthritis and systemic sclerosis; in the latter it is a major cause of morbidity and mortality. In other cases patients present with diffuse pulmonary fibrosis of unknown aetiology and a diagnosis of cryptogenic fibrosing alveolitis (idiopathic pulmonary fibrosis) is made.

The pathogenesis of cryptogenic fibrosing alveolitis remains unclear and current treatment is frequently unrewarding. A recent study showed only $50 \%$ survival five years after presentation despite treatment. ${ }^{2}$ Prevalence in the $\mathrm{UK}$ is estimated at three per 100000 over the age of 50 and annual mortality, currently $1200-1400$, is increasing. ${ }^{3}$ The disease therefore presents a major challenge to respiratory physicians and researchers and it is hoped that with improved understanding of the pathogenesis more successful treatments will be developed.

One current hypothesis for the development of pulmonary fibrosis is that polypeptide mediators, or cytokines, derived both from resident cells and from inflammatory cells entering the lung, stimulate fibroblasts to synthesise excessive amounts of extracellular matrix including collagen. Subsequent deposition of this matrix in the alveolar walls impedes gas exchange between air and blood and results in the characteristic features of a restrictive defect on lung function testing with reduced gas transfer.

One such group of mediators is the transforming growth factor $\beta$ (TGF- $\beta$ ) family. This comprises at least five peptides and belongs to the TGF- $\beta$ supergene family which includes the mammalian inhibins, activins, and
Mullerian inhibitory substances. ${ }^{4}$ These peptides have in common the ability to regulate developmental processes. TGF- $\beta_{1}$ was first discovered in 1983 and purified from human platelets, placenta, and bovine kidney. Its name was originally based on its ability to induce a transformed phenotype in mesenchymal cells, but it is now known to affect numerous functions in nearly all cells. It is produced by a number of cells in the lung including macrophages, epithelial cells, and fibroblasts.

TGF- $\beta$ stimulates fibroblasts to synthesise collagen and fibronectin, ${ }^{5}$ and smooth muscle cells to synthesise elastin. ${ }^{6}$ In addition it promotes matrix accumulation by decreasing collagenase synthesis and increasing the production of collagenase inhibitors such as tissue inhibitor metalloproteinase (TIMP) and alpha-2 macroglobulin. It also increases the transcription, translation, and processing of cellular receptors for matrix proteins, suggesting that it may modify cellular interactions with extracellular matrix. Under some circumstances TGF- $\beta$ can also stimulate fibroblast growth. ${ }^{7}$

A role for TGF- $\beta$ s has been postulated in normal wound healing. In newborn mice subcutaneous injection of TGF- $\beta$ induces formation of granulation tissue at the injection site. ${ }^{8}$ Neutralising antibody to TGF- $\beta$ reduces scarring during wound healing in adult rats. ${ }^{9}$ TGF- $\beta$ may also operate in the pathogenesis of disease, and a role for it has been proposed in fibrotic disorders of kidney and liver. Recently Border and colleagues suggested that the fibrosis associated with experimental glomerulonephritis could be suppressed with a TGF- $\beta$ antiserum ${ }^{10}$ or with decorin, ${ }^{11}$ a matrix component which binds TGF- $\beta$ and neutralises its biological activity.

In respiratory research there has also been interest in this mediator. TGF- $\beta$ is present in bronchoalveolar lavage fluid in normal human subjects. ${ }^{12}$ TGF- $\beta_{1}$ levels are increased in the lungs in animal models of pulmonary fibrosis ${ }^{13}$ and the peptide is present at sites of extracellular matrix deposition in patients with cryptogenic fibrosing alveolitis. ${ }^{1415}$ The genes producing TGF- $\beta_{1}$ are also reported to be activated. ${ }^{1416}$ TGF- $\beta$ levels have also been shown to be increased in a mouse model of hypersensitivity pneumonitis. ${ }^{17}$

In this issue of Thorax Giri and colleagues ${ }^{18}$ (pp 959-966) provide a further piece of evidence to implicate TGF- $\beta$ in the pathogenesis of pulmonary fibrosis. They show that antibodies to both TGF- $\beta_{1}$ and TGF- $\beta_{2}$ attenuate the collagen deposition which occurs in mice after injection of the antineoplastic agent bleomycin. This 
drug causes pulmonary fibrosis in a small proportion of patients who receive it for the treatment of carcinoma, a property which has been harnessed in developing animal models of pulmonary fibrosis. ${ }^{19}$ These models have been proposed to emulate cryptogenic fibrosing alveolitis. However, since the time course of fibrosis is rapid, evolving over a few weeks, they may represent a better model of acute lung injury.

How significant are these results, both to our understanding of pathogenesis and to progress with new pharmacological interventions in patients with pulmonary fibrosis? With regard to our understanding of pathogenesis, this study yields new insight. A number of mediators with profibrotic properties are known to be present in the lungs of patients with pulmonary fibrosis, other examples being platelet derived growth factor and insulin like growth factor 1 . Their relative importance in vivo is very poorly understood. These results are therefore of value in implicating the TGF- $\beta$ family. That these TGF- $\beta$ antibodies only partially ameliorated the fibrosis suggests either that other mediators, including TGF- $\beta_{3}$, are also playing a role in this model, or that insufficient antibody was given. These positive results might encourage other workers to perform similar studies with antibodies directed at other mediators considered to be driving pulmonary fibrosis.

As a new therapeutic regime the approach described here is of interest, but it might be wise to express caution. The authors gave these antibodies to mice immediately after initiating pulmonary fibrosis. Such a luxury is not usually available to clinicians. It has been suggested that earlier disease may respond better to treatment ${ }^{20}$ but patients usually present relatively late in the course of disease, presumably months or years after the initiating stimulus.

The systemic, intravenous administration of complex proteins to patients is fraught with potential problems. This study has clearly shown, however, that the fibrotic process can be modified by inhibiting the action of TGF$\beta$ s. It may therefore be worthwhile trying to develop other means of blocking the action of TGF- $\beta \mathrm{s}$. The role of receptor antagonists and TGF- $\beta$ binding proteins could be explored. Such strategies are being developed in other areas. Compounds derived from natural cytokine antagonists, such as tumour necrosis factor and interleukin 1 inhibitors, have been evaluated in animal models of septic shock ${ }^{21}$ and arthritis, ${ }^{22}$ respectively. This approach, which could also be applied to other contributory growth factors, is particularly important given the relative lack of success with alternative agents. ${ }^{23}$ Increased awareness of potential new treatments may also encourage earlier diagnosis and referral to specialist treatment centres, resulting in a more favourable prognosis for these patients.

It would also be encouraging if these results were to stimulate further interest by the pharmaceutical industry in treatment for the fibrotic process. It is becoming increasingly recognised that fibrosis is a component of a wide range of diseases. Extrapulmonary examples include hepatic cirrhosis, chronic glomerulonephritis, Crohn's disease, keloid formation, and scar formation following burns or other forms of skin trauma. It is hoped that, as research into these related areas is pursued, a better out- come may also be obtained for patients with lung fibrosis.

\begin{tabular}{|c|}
\hline $\begin{array}{r}\text { G J LAURENT } \\
\text { R K COKER } \\
\text { R J McANULTY } \\
\text { Department of Thoracic Medicine, } \\
\text { National Heart and Lung Institute, } \\
\text { Emmanuel Kaye Building, } \\
\text { Manresa Road, 을 } \\
\text { London SW3 } 6 L R\end{array}$ \\
\hline
\end{tabular}

Reprint requests to: Dr G J Laurent

1 Suffredini AF, Ognibene FP, Lack EE, Simmons JT, Brenner M, Gill VJ, et al. Nonspecific interstitial pneumonitis: a common cause of pulmonary disease in the acquired immunodeficiency syndrome. Ann $\bar{\sigma}$ Intern Med 1987;107:7-12.

2 Johnson MA, Kivan S, Snell NJC, Nunn AJ, Darbyshire JH, TurnerWarwick $M$. Randomised controlled trial comparing prednisolone alone $\varrho$ with cyclophosphamide and low dose prednisolone in combination in cryptogenic fibrosing alveolitis. Thorax 1989;44:280-8.

3 Johnston I, Britton J, Kinnear W, Logan R. Rising mortality from crypto- $\overrightarrow{0}$ genic fibrosing alveolitis. BMF 1990;301:1017-21.

4 Roberts AB, Sporn MB. The transforming growth factor $\beta$ s. In: Peptide $\overrightarrow{\vec{\omega}}$ growth factors and their receptors. Handbook of experimental pharmacology. $\omega$ Vol 95/1. Heidelberg: Springer-Verlag 1990:419-72.

5 Ignotz RA, Massague J. Transforming growth factor $\beta$ stimulates the $\overrightarrow{\vec{x}}$ expression of fibronectin and collagen and their incorporation into the extracellular matrix. F Biol Chem 1986;261:4337-45.

$6 \mathrm{Liu}$ J-M, Davidson JM. The elastogenic effect of recombinant transforming growth beta on porcine aortic smooth muscle cells. Biochem Biophys Res Commun 1988;154:895-901.

7 Hill DJ, Strain AJ, Elstow SF, Swenne I, Milner RDG. Bifunctional action of transforming growth factor $\beta$ on DNA synthesis in early pas- $ᄋ$ sage human fetal fibroblasts. $f$ Cell Physiol 1986;128:322-8.

8 Roberts AB, Sporn MB, Assoian RK, Smith JM, Roche NS, Wakefield $\mathrm{LM}$, et al. Transforming growth factor $\beta$ : rapid induction of fibrosis and angiogenesis in vivo and stimulation of collagen formation in vitro. Proc $\frac{\Omega}{\circ}$ Natl Acad Sci USA 1986;83:4167-71.

9 Shah M, Foreman DM, Ferguson MWJ. Control of scarring in adult $\mathbb{D}$ wounds by neutralising antibody to transforming growth factor $\beta$. Lancet 1992;339:213-4.

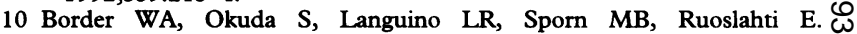
Suppression of experimental glomerulonephritis by antiserum against transforming growth factor $\beta_{1}$. Nature 1990;346:371-4.

11 Border WA, Noble NA, Yamamoto T, Harper JR, Yamaguchi Y, Pierschbacher MD, et al. Natural inhibitor of transforming growth factor $\beta$ protects against scarring in experimental kidney disease. Nature $\bar{O}$ 1992;360:361-4.

12 Yamauchi K, Martinet Y, Basset P, Fells GA, Crystal RG. High levels of $\mathbb{Q}$ transforming growth factor $\beta$ are present in the epithelial lining fluid of the normal human lower respiratory tract. Am Rev Respir Dis 1988;137:1360-3.

13 Khalil N, Bereznay O, Sporn M, Greenberg AH. Macrophage production of transforming growth factor $\beta$ and fibroblast collagen synthesis in chronic pulmonary inflammation. $\mathcal{F}$ Exp Med 1989;170:727-37.

14 Broekelmann TJ, Limper AH, Colby TV, McDonald JA. Transforming growth factor $\beta_{1}$ is present at sites of extracellular matrix expression in human pulmonary fibrosis. Proc Natl Acad Sci 1991;88:6642-6.

15 Khalil N, O'Connor RN, Unruh HW, Warren PW, Flanders KC, Kemp $\times$ $A$, et al. Increased production and immunohistochemical localisation of $O$ transforming growth factor $\beta$ in idiopathic pulmonary fibrosis. Am 73 transforming growth factor $\beta$ in 1 .

16 Raghow R, Irish P, Kang AH. Coordinated regulation of transforming growth factor $\beta$ gene expression and cell proliferation in hamster lungs undergoing bleomycin-induced pulmonary fibrosis. $f$ Clin Invest $\mathrm{O}$ 1989;84:1836-42.

17 Denis $M$, Ghadirian E. Transforming growth factor $\beta$ is generated in the $D$ course of hypersensitivity pneumonitis: contribution to collagen synthesis. Am $\mathcal{F}$ Respir Cell Mol Biol 1992;7:156-60.

18 Giri SN, Hyde DM, Hollinger MA. Effect of antibody to transforming $\mathrm{N}$ growth factor $\beta$ on bleomycin induced accumulation of lung collagen in mice. Thorax 1993;48:959-66.

19 Fine A, Goldstein RH, Snider GL. Animal models of pulmonary fibrosis. N In: Crystal RE, West JB, eds. The Lung: Scientific Foundations. New $\omega$ York: Raven Press, 1991:2047-57.

20 Turner-Warwick M, Burrows B, Johnson A. Cryptogenic fibrosing alve- 6 olitis: the response to corticosteroid treatment and its effect on survival. Thorax 1980;35:593-9.

21 Dinarello CA, Gelfand JA, Wolff SM. Anticytokine strategies in the treatment of the systemic inflammatory response syndrome. $\mathscr{A} A M A$ 1993;269:1829-35.

22 Dinarello CA, Thompson RC. Blocking IL-1: interleukin 1 receptor antagonist in vivo and in vitro. Immunol Today 1991;12:404-10.

23 Laurent GJ, Harrison NK, McAnulty RJ. The regulation of collagen production in normal lung and during interstitial lung disease. Postgrad Med 7 1988;64(Suppl):26-34. 